\title{
Differences in genomic instability between intestinal- and diffuse-type gastric cancer
}

\author{
Matti Vauhkonen ${ }^{1}$, Hanna Vauhkonen ${ }^{2,3}$, Antti Sajantila ${ }^{2}$, and Pentti Sipponen ${ }^{3}$ \\ ${ }^{1}$ Department of Medicine, HUCH, Jorvi Hospital, Turuntie 150, 02740 Espoo, Finland \\ ${ }^{2}$ Department of Forensic Medicine, University of Helsinki, Helsinki, Finland \\ ${ }^{3}$ Department of Pathology, HUSLAB, Jorvi Hospital, Espoo, Finland
}

\begin{abstract}
Background. Microsatellite instability (MSI) and loss of heterozygosity $(\mathrm{LOH})$ are lesions in the genome found with different frequencies in gastric carcinomas (GCAs). Despite a great body of studies, no systematic approach to the detailed classification of MSI and $\mathrm{LOH}$ in the two major types of GCA has been published.

Methods. Thirty-seven advanced GCAs, 25 intestinal-type (IGCAs) and 12 diffuse-type (DGCAs), were assayed with 15 autosomal tetranucleotide markers on 14 chromosomal arms. The observed frequencies and types of microsatellite alterations allowed stratification into subgroups, i.e., highand low-grade MSI (MSI-H, MSI-L) or microsatellite-stable (MSS), and high- or low-grade, or non-detectable LOH (LOH-H, LOH-L, LOH-N).

Results. Collectively, the markers detected MSI-H tumors with sensitivity equal to that of BAT-26 (a single marker highly specific for MSI-H). Likewise, the markers detected LOH at chromosomal arms $5 q, 18 q$, and $21 q$ with a sensitivity equal to markers used previously. Seven (19\%) MSI-H and six (16\%) LOH-H tumors were found, with a significant association $(P=0.027)$ with IGCA: $92 \%$ of MSI-H and LOH-H occurred in IGCA patients only. Conversely, in DGCA, a significantly higher prevalence of a stable (LOH-N/MSS) phenotype was found as compared with IGCA (75.1\% vs $\mathbf{2 8 . 0} \%$; $P=0.035)$. The MSI-L phenotype was found in $57.9 \%$ of nonMSI-H IGCA tumors and was associated significantly $(P=$ 0.015) with LOH-H.

Conclusion. A clear difference in genomic instability between IGCA and DGCA was found. In IGCA, the MSI and LOH pathways were more commonly involved, whereas in DGCA, a stable phenotype was predominant. As a novel finding, MSI$L$ as a true phenomenon and its association with $\mathrm{LOH}$ was observed in IGCA.
\end{abstract}

Key words Stomach cancer · Microsatellite instability $\cdot$ Loss of heterozygosity $\cdot$ Genomic instability

Offprint request to: $\mathrm{M}$. Vauhkonen

Received: December 6, 2004 / Accepted: July 19, 2005

\section{Introduction}

Intestinal gastric carcinoma (IGCA) and diffuse (DGCA) forms are the two main morphological types of gastric carcinoma (GCA) [1-3]. These tumor types diverge in many demographic and clinical characteristics [4,5]. Molecular genetic studies indicate that these types differ in pathogenesis, based on dissimilar errors and expression of various genes. However, no single genomic abnormality is known to be specific to sporadic GCA, or to any of its histological subtypes, as recently reviewed by Tahara [6]. In the initiation and promotion of gastric cancer microsatellite instability (MSI) [7-10], loss of heterozygosity ( $\mathrm{LOH})[7,11,12]$ and DNA amplification $[13,14]$ have been described. Determination of the MSI or LOH rate by microsatellites may depend on methodological factors such as the set and number of markers used [15-18], artifacts due to degraded DNA in paraffin-embedded tissue samples [19], or a low number of cancer cells in the tissue sample [20].

The MSI phenotype is characterized by new alleles not present in the normal genotype. Depending on the rate of unstable loci, MSI tumors can be divided into two categories, i.e., MSI-low (MSI-L) and MSIhigh (MSI-H) types. MSI-H is a well-established phenotype in gastrointestinal epithelial neoplasias, which results from malfunction of the mismatch repair (MMR) system, caused mainly by hypermethylation of the $h M L H 1$ promoter $[9,21,22]$. The target genes for MSI-H-driven carcinogenesis, such as TGF- $\beta, B A X$, $h M S H 3$, and $h M S H 6$, contain coding repeats in which frameshift mutations produce aberrant protein products [23]. The existence and importance of MSI-L is still unclear, because all gastrointestinal tumors may show a background level of MSI, which has been proposed to be due to clonal expansion at normal mutation rates [16-18].

$\mathrm{LOH}$ is considered to be a marker of chromosomal instability, but its mechanisms are poorly understood 
[24]. It may indicate a second inactivational hit of a cancer gene and, thus, its frequency may correlate with the level of chromosomal instability, as reviewed earlier $[20,25]$. The occurrence of LOH and MSI-H phenotypes in tumors is thought to be mutually exclusive [15,25]; however, contradicting data have been recently published [26-30]. Several studies of GCA have focused on $\mathrm{LOH}$ at one or a few specific loci on cancer-associated chromosomal arms $[7,11,26,27]$, where no consistent differences in $\mathrm{LOH}$ frequency between gastric cancer types have been detected. IGCA has been shown to harbor more LOH and MSI-H than DGCA [12]. In recent studies of colorectal cancer [29,30], overlapping phenotypes, where MSI and LOH coexist, have been found. However, respective data from gastric cancers are lacking.

In our previous studies, we found that MSI and LOH in gastrointestinal tumors could be detected by using tetranucleotide markers, which are highly polymorphic and heterozygous, with minimal stutter artifacts [31]. We also found that, using a set of these markers, they collectively revealed the same MSI-H tumors that were detectable by BAT-26 $[9,32]$. The aim of the present study was to use these markers in the assessment of differences in the genetic integrity of IGCA and DGCA. Association between the microsatellite phenotypes and clinicopathological parameters of GCA was also studied.

\section{Patients, materials, and methods}

\section{Samples}

Surgically resected tissue specimens from 37 advanced primary gastric cancers (25 IGCA and 12 DGCA) and their cancer-free adjacent areas were collected during the period 1996-2003 at the Department of Pathology of Jorvi Hospital, Espoo, Finland. After excision, the tissues were snap-frozen in liquid nitrogen, overlayed with Tissue-Tek OCT Compound (Sakura Finetek, Zoetervoude, Netherlands) and stored at $-70^{\circ} \mathrm{C}$. Histopathologic diagnosis of the tumor tissues and classification into intestinal and diffuse types was based on the WHO and Laurén classifications [1,2] and was done by one experienced pathologist (P.S.). The samples were verified by microscopy to contain at least $50 \%$ cancer tissue as estimated semiquantitatively from the total epithelial tissue volume in the cancer specimen. Staging of the tumor was done according to the International Union Against Cancer (UICC) TNM system. Hereditary nonpolyposis colon cancer (HNPCC) syndrome and familial gastric cancer were excluded by taking patient history from documents.

\section{DNA preparation and microsatellite phenotyping}

The DNA was extracted from $200-500 \mathrm{mg}$ of freshfrozen tissue by digestion with proteinase $\mathrm{K}$ and filtration through Qiaquick columns (Qiagen, Hilden, Germany) and was used in subsequent polymerase chain reactions (PCR) reactions in 0.1- to 1-ng aliquots, as described in detail previously [31]. Two commercially available kits, AmpFlSTR SGM Plus and AmpFlSTR Profiler (Applied Biosystems, Foster City, CA, USA), together containing 15 autosomal markers, were used to detect the allelic alterations of the tumors in comparison to their healthy adjacent tissues. The PCR amplifications and analysis, carried out by ABI Prism CE310 capillary electrophoresis (Applied Biosystems), were performed as described previously [31]. MSI was identified in a tumor tissue by alleles not present in the control tissue. Using the suggested criteria [15], the tumors were categorized into three MSI phenotypes: MSI-H, with extra alleles at $33 \%$ or more of the loci; MSI-L, with extra alleles at fewer than $33 \%$ of the loci; and microsatellite-stable (MSS), tumors with no alterations. The MSI-H status was confirmed by amplification of the BAT-26 locus [9,32], where the shortening of monomorphic alleles was observed in the MSI-H tumors. LOH was observed as allele peak ratios below 0.5 in the tumor tissue. Only the non-MSI-H tumors with heterozygote control tissues were considered as informative for LOH. A 25\% cutoff level for the proportion of LOH among informative markers was applied to distinguish high- and low-level LOH (LOH-H and LOH-L), as described previously [7]. Samples with no alterations of $\mathrm{LOH}$ type were categorized as $\mathrm{LOH}-$ non detectable $(\mathrm{LOH}-\mathrm{N})[7,12]$.

\section{Statistics}

Fisher's exact test, the $\chi^{2}$ test, the Mann-Whitney $U$-test, and an independent t-test were performed, using SPSS software (SPSS, Chicago, IL, USA). A $P$ value of less than 0.05 was considered significant.

\section{Ethics}

This study protocol was evaluated and approved by the Institutional Ethics Committee of the University Hospital Helsinki.

\section{Results}

Our set of 15 markers and their locations on the 14 chromosomal arms are shown in Table 1 . A significantly higher frequency of $\mathrm{LOH}(P<0.001)$ was found in IGCA as compared with DGCA tumors. A high 
Table 1. Chromosomal location of the microsatellite markers and proportion of LOH at the loci

\begin{tabular}{|c|c|c|c|}
\hline \multirow[b]{2}{*}{ Locus name } & \multirow{2}{*}{$\begin{array}{c}\text { Chromosomal } \\
\text { location }^{\mathrm{a}}\end{array}$} & \multicolumn{2}{|c|}{$\mathrm{LOH}$ at informative cases $(\%)^{\mathrm{b}}$} \\
\hline & & $\mathrm{IGCA}^{\mathrm{c}}$ & DGCA \\
\hline TPOX & $2 \mathrm{p} 25.3$ & $2 / 13(15 \%)$ & $0 / 4(0 \%)$ \\
\hline D2S1338 & $2 q 35$ & $4 / 15(27 \%)$ & $0 / 7(0 \%)$ \\
\hline D3S1358 & $3 \mathrm{p} 21.31$ & $0 / 11(0 \%)$ & $0 / 4(0 \%)$ \\
\hline FGA & $4 \mathrm{q} 31.3$ & $3 / 13(23 \%)$ & $0 / 7(0 \%)$ \\
\hline D5S818 & $5 q 23.2$ & $2 / 13(15 \%)$ & $0 / 8(0 \%)$ \\
\hline CSF1PO & $5 q 33.1$ & $3 / 15(20 \%)$ & $1 / 7(14 \%)$ \\
\hline D7S820 & $7 \mathrm{q} 21.11$ & $3 / 12(25 \%)$ & $0 / 5(0 \%)$ \\
\hline D8S1179 & $8 q 24.13$ & $0 / 14(0 \%)$ & $0 / 8(0 \%)$ \\
\hline TH01 & $11 \mathrm{p} 15.5$ & $1 / 13(8 \%)$ & $0 / 8(0 \%)$ \\
\hline VWA & $12 \mathrm{p} 13.31$ & $3 / 13(23 \%)$ & $0 / 7(0 \%)$ \\
\hline D13S317 & $13 \mathrm{q} 31.1$ & $1 / 15(7 \%)$ & $0 / 5(0 \%)$ \\
\hline D16S539 & $16 \mathrm{q} 24.1$ & $3 / 15(20 \%)$ & $0 / 7(0 \%)$ \\
\hline D18S51 & $18 \mathrm{q} 21.33$ & $3 / 15(20 \%)$ & $0 / 6(0 \%)$ \\
\hline D19S433 & $19 \mathrm{q} 12$ & $0 / 12(0 \%)$ & $0 / 8(0 \%)$ \\
\hline D21S11 & $21 \mathrm{q} 21.1$ & $5 / 18(28 \%)$ & $0 / 7(0 \%)$ \\
\hline
\end{tabular}

LOH, loss of heterozygosity

${ }^{\text {a }}$ Data from the EMBL database (www.ensembl.org)

${ }^{\mathrm{b}}$ Percentage of LOH in informative cases

${ }^{c} P<0.001$ (Mann-Whitney $U$-test) for difference in LOH frequency between IGCA and DGCA

Table 2. Comparison of rates of $\mathrm{LOH}$ at different loci on the indicated chromosomal arms

\begin{tabular}{|c|c|c|c|c|c|c|}
\hline Reference no. ${ }^{a}$ & $5 q$ & & $18 \mathrm{q}$ & & $21 q$ & \\
\hline Present study & $\begin{array}{l}\text { D5S818 (5q23.2) } \\
\text { CSFIPO (5q33.1) }\end{array}$ & $\begin{array}{l}15 \% \\
27 \%\end{array}$ & D18S51 (18q21.33) & $20 \%$ & D21S11 (21q21.1) & $28 \%$ \\
\hline 11 & D5S409 (5q21.1) & $33 \%$ & D18S69 (18q21.1) & $32 \%$ & D21S1436 (21q21.1) & $43 \%$ \\
\hline 7 & $\begin{array}{l}\text { D5S349 (5q13.3) } \\
\text { D5S409 (5q21.1) } \\
\text { D5S346 (5q22.2) } \\
\text { D5S519 (5q33.1) } \\
\text { D5S422 (5q34) }\end{array}$ & $\begin{array}{l}29 \% \\
31 \% \\
37 \% \\
33 \% \\
34 \%\end{array}$ & $\begin{array}{l}\text { D18S67 (18q12.2) } \\
\text { D18S57 (18q12.2) } \\
\text { D18S474 (18q21.1) } \\
\text { D18S58 (18q22.3) } \\
\text { D18S70 (18q23) }\end{array}$ & $\begin{array}{l}38 \% \\
43 \% \\
37 \% \\
37 \% \\
42 \%\end{array}$ & NA & \\
\hline 26 & D5S409 (5q21.1) & $50 \%$ & D18S69 (18q21.1) & $36 \%$ & D21S1436 (21q21.1) & $40 \%$ \\
\hline 27 & $\begin{array}{l}\text { D5S299 (5q15-13) } \\
\text { D5S409 (5q21.1) }\end{array}$ & $\begin{array}{l}32 \% \\
27 \%\end{array}$ & $\begin{array}{l}\text { D18S70 (18q21.1) } \\
\text { DCC (18q21.1) } \\
\text { D18S386 (18q22.1) }\end{array}$ & $\begin{array}{l}23 \% \\
48 \% \\
42 \%\end{array}$ & $\mathrm{D} 21 \mathrm{~S} 258(21 \mathrm{q} 11)^{\mathrm{d}}$ & $23 \%$ \\
\hline
\end{tabular}

NA, not analyzed

${ }^{a}$ Data represent mostly intestinal (differentiated) gastric adenocarcinomas

${ }^{\mathrm{b}}$ Data for chromosomal locations from www.ensembl.org

${ }^{\mathrm{c}}$ Chromosomal locations adopted from references $7,11,26,27$

variation in the frequency of $\mathrm{LOH}$ was also observed between individual markers. Four of the markers used in the present study (D5S818, CSFIPO, D18S51, D21S11) were located in regions which have been shown to be non-randomly lost during the progression of GCA [26] (Table 2). These chromosomal arms, 5q, $18 \mathrm{q}$, and $21 \mathrm{q}$, have been shown to contain the tumor suppressor genes $A P C$ and $M C C$ [33], DCC [34], and trefoil factor 1 [35], respectively. Our tetranucleotide markers reported a rate of $\mathrm{LOH}$ of about $20 \%$ in the corresponding chromosomal region, consistent with previous reports (Table 2). Collectively, the markers were sensitive for MSI, and they found the same MSI-H tumors that were detectable by BAT-26 (data not shown), in agreement with our previous findings [31].

The microsatellite phenotypes of the GCAs and their numbers and proportions found are provided in Tables 3 and 4 . MSI-H was found in $24.0 \%$ of IGCA tumors and in $8.3 \%$ of DGCA tumors. LOH-H was found in $24 \%$ of IGCA tumors, whereas in DGCA tumors this phenotype was absent. The IGCAs included significantly more $(48.0 \% ; P=0.027)$ cases with severe genetic lesions (MSI-H and LOH-H) than the DGCAs (8.3\%; 
Table 3. Tumor specimens analyzed in the study

\begin{tabular}{|c|c|c|c|}
\hline Sample number & Histologic type & LOH type & MSI type \\
\hline 57 & DGCA & LOH-N & MSS \\
\hline 78 & DGCA & LOH-N & MSS \\
\hline 90 & DGCA & LOH-N & MSS \\
\hline 102 & DGCA & LOH-N & MSS \\
\hline 175 & DGCA & LOH-N & MSS \\
\hline 177 & DGCA & LOH-N & MSS \\
\hline 178 & DGCA & LOH-N & MSS \\
\hline 147 & DGCA & LOH-N & MSS \\
\hline 50 & DGCA & LOH-N & MSS \\
\hline 151 & DGCA & LOH-N & MSI-L \\
\hline 97 & DGCA & LOH-L & MSS \\
\hline 176 & DGCA & ND & MSI-H \\
\hline 1 & IGCA & $\mathrm{LOH}-\mathrm{N}$ & MSS \\
\hline 6 & IGCA & LOH-N & MSS \\
\hline 62 & IGCA & LOH-N & MSS \\
\hline 114 & IGCA & LOH-N & MSS \\
\hline 136 & IGCA & LOH-N & MSS \\
\hline 157 & IGCA & LOH-N & MSS \\
\hline 2 & IGCA & LOH-N & MSS \\
\hline 119 & IGCA & LOH-N & MSI-L \\
\hline 150 & IGCA & LOH-N & MSI-L \\
\hline 186 & IGCA & LOH-N & MSI-L \\
\hline 188 & IGCA & LOH-N & MSI-L \\
\hline 72 & IGCA & LOH-L & MSI-L \\
\hline 158 & IGCA & LOH-L & MSS \\
\hline 154 & IGCA & LOH-H & MSI-L \\
\hline 155 & IGCA & LOH-H & MSI-L \\
\hline 7 & IGCA & LOH-H & MSI-L \\
\hline 189 & IGCA & LOH-H & MSI-L \\
\hline 194 & IGCA & LOH-H & MSI-L \\
\hline 99 & IGCA & LOH-H & MSS \\
\hline 4 & IGCA & ND & MSI-H \\
\hline 49 & IGCA & ND & MSI-H \\
\hline 55 & IGCA & ND & MSI-H \\
\hline 87 & IGCA & ND & MSI-H \\
\hline 191 & IGCA & ND & MSI-H \\
\hline 195 & IGCA & ND & MSI-H \\
\hline
\end{tabular}

DGCA, diffuse-type gastric cancer; IGCA, intestinal-type gastric cancer; LOH-N, LOH-nondetectable; LOH-L, LOH-low; LOH-H, LOH-high; MSS, microsatellite-stable; MSI-L, MSI-low; MSI-H, MSI-high; ND, not detected

${ }^{a}$ MSI-H and LOH are considered to be mutually exclusive [15]

Table 4. Numbers and proportions of MSI and LOH phenotypes in gastric cancers

\begin{tabular}{|c|c|c|c|c|}
\hline \multirow[b]{2}{*}{ LOH type } & \multirow[b]{2}{*}{ MSI type } & \multirow{2}{*}{$\frac{\text { IGCA }(n=25)}{n(\%)}$} & \multirow{2}{*}{$\frac{\text { DGCA }(n=12)}{n(\%)}$} & \multirow[b]{2}{*}{$P$ value } \\
\hline & & & & \\
\hline ND & MSI-H & $6(24.0)$ & $1(8.3)$ & $P=0.027^{\mathrm{b}}$ \\
\hline LOH-H & MSI-L & $5(20.0)$ & 0 & $P=0.015^{\mathrm{c}}$ \\
\hline LOH-H & MSS & $1(4.0)$ & 0 & \\
\hline LOH-L & MSI-L & $1(4.0)$ & 0 & \\
\hline LOH-L & MSS & $1(4.0)$ & $1(8.3)$ & \\
\hline LOH-N & MSI-L & $4(16.0)$ & $1(8.3)$ & $P=0.023^{\mathrm{d}}$ \\
\hline LOH-N & MSS & $7(28.0)$ & $9(75.1)$ & $P=0.035^{\mathrm{e}}$ \\
\hline
\end{tabular}

ND, not detected

${ }^{\text {a }}$ Fisher's exact test

${ }^{b}$ Difference in prevalence of LOH-H and MSI-H in IGCA vs DGCA

${ }^{c}$ Difference in prevalence of MSI-L in LOH-H vs LOH-N tumors

${ }^{\mathrm{d}}$ Difference in prevalence of MSI-L between non-MSI IGCA vs DGCA

${ }^{\mathrm{e}}$ Difference in prevalence of LOH-N/MSS genotype in IGCA vs DGCA 
Table 5. Clinicopathological features of the gastric cancers

\begin{tabular}{|c|c|c|c|c|c|}
\hline \multicolumn{2}{|c|}{ Microsatellite phenotype } & LOH-N $(n=21)$ & $\mathrm{LOH}(n=9)$ & MSI-H $(n=7)$ & $P$ value ${ }^{\mathrm{a}}$ \\
\hline \multicolumn{6}{|l|}{$\operatorname{Sex}(M / F)$} \\
\hline All & & $14 / 7$ & $5 / 4$ & $3 / 4$ & 0.519 \\
\hline \multicolumn{6}{|l|}{ Site } \\
\hline \multirow[t]{2}{*}{ IGCA } & Distal & 10 & 5 & 5 & 0.303 \\
\hline & Proximal & 1 & 3 & 1 & \\
\hline \multirow[t]{2}{*}{ DGCA } & Distal & 5 & 0 & 1 & 0.368 \\
\hline & Proximal & 5 & 1 & 0 & \\
\hline \multicolumn{6}{|l|}{ Tumor } \\
\hline \multirow[t]{2}{*}{ IGCA } & $\mathrm{T} 0-\mathrm{T} 2$ & 2 & 2 & 0 & 0.544 \\
\hline & $\mathrm{T} 3-\mathrm{T} 4$ & 9 & 6 & 6 & \\
\hline \multirow{2}{*}{ DGCA } & $\mathrm{T} 0-\mathrm{T} 2$ & 2 & 0 & 0 & 0.787 \\
\hline & T3-T4 & 8 & 1 & 1 & \\
\hline \multicolumn{6}{|l|}{ Nodes } \\
\hline \multirow[t]{2}{*}{ IGCA } & N0-N1 & 9 & 6 & 6 & 0.435 \\
\hline & $\mathrm{N} 2-\mathrm{N} 3$ & 2 & 2 & 0 & \\
\hline \multirow[t]{2}{*}{ DGCA } & N0-N1 & 8 & 1 & 1 & 0.787 \\
\hline & $\mathrm{N} 2-\mathrm{N} 3$ & 2 & 0 & 0 & \\
\hline \multicolumn{6}{|l|}{ Stage } \\
\hline \multirow[t]{2}{*}{ IGCA } & I-II & 4 & 2 & 5 & 0.139 \\
\hline & III-IV & 7 & 6 & 1 & $0.056^{\mathrm{b}}$ \\
\hline \multirow[t]{2}{*}{ DGCA } & I-II & 6 & 1 & 0 & 0.345 \\
\hline & III-IV & 4 & 0 & 1 & \\
\hline \multicolumn{6}{|l|}{ Grade } \\
\hline \multirow[t]{2}{*}{ IGCA } & G I & 3 & 2 & 0 & 0.119 \\
\hline & G II-III & 8 & 6 & 6 & \\
\hline \multicolumn{6}{|l|}{ Mean age ${ }^{f}$} \\
\hline \multirow{2}{*}{\multicolumn{2}{|c|}{ All }} & 67.5 & 73.0 & 76.3 & $0.062^{c}$ \\
\hline & & 70.4 & 74.8 & 77.2 & $0.011^{\mathrm{d}}$ \\
\hline \multicolumn{2}{|l|}{ DGCA } & 64.4 & $58.8^{\mathrm{e}}$ & $70.6^{\mathrm{e}}$ & \\
\hline
\end{tabular}

${ }^{\mathrm{a}} \chi^{2}$ test

${ }^{\mathrm{b}} P$ value for stage of MSI-H vs LOH-N and LOH genotypes in IGCA (Fisher's exact test)

${ }^{c} P$ value for age at detection of MSI-H vs LOH-N tumors $(t$-test $)$

${ }^{\mathrm{d}} P$ value for mean age at diagnosis; IGCA vs DGCA ( $t$-test)

e only one patient

${ }^{\mathrm{f}}$ At diagnosis

Table 4). However, the difference between the two cancer types in the prevalence of MSI-H or LOH-H alone did not reach statistical significance. MSI-L was found in $40 \%(12 / 30)$ of the non-MSI-H GCAs, and was associated significantly $(P=0.023)$ with IGCA $(57.9 \% ; 11 /$ $19)$ as compared with DGCA $(9.1 \% ; 1 / 11)$. Further, MSI-L was found in $83 \%(5 / 6)$ of LOH-H, 33\% (1/3) of LOH-L, and in $24 \%(5 / 21)$ of LOH-N tumors. Among these non-MSI-H GCAs, a significant $(P=0.015)$ concordance between the rates of MSI-L and LOH was noted (Table 4). Collectively, $43 \%$ of the sporadic GCAs were found to be genetically stable (LOH-N/ MSS $)$, with a significant $(P=0.035)$ association with DGCA (75\%), as compared with IGCA (28\%).

No significant differences were found between the various clinicopathological parameters of GCA and the microsatellite phenotypes (Table 5). MSI-H tumors tended to represent a lower clinical stage than LOH-N/ LOH tumors. On average, the DGCA patients were younger (64.6 years; $P=0.011$ ) than the IGCA patients (74.8 years). Age at the time of detection of the MSI-H cancers tended to be higher ( 76.3 years; $P=0.062$ ) than the age of LOH-N patients (67.5 years).

\section{Discussion}

Initially, we evaluated the validity of the tetranucleotide markers in $\mathrm{LOH}$ detection by comparing the rates of $\mathrm{LOH}$ at four chromosomal regions with the previously published data, as summarized in Table 2. The results show that very similar $\mathrm{LOH}$ rates (about $20 \%-40 \%$ ) were observed for the tetranucleotide markers and for markers used in other studies. In addition, a perfect match in the MSI-H detection between our panel of 15 markers and BAT-26 was observed (data not shown). We thus conclude that the markers used here are valid for the determination of LOH and MSI in IGCA and DGCA.

The higher prevalence of MSI-H in IGCA than in DGCA found in our study is in line with previous results of $15 \%-23 \%$ and $2.5 \%-7.7 \%$ for MSI-H in IGCA 
and DGCA, respectively [7,11,12,36-38]. Previously, IGCA has been reported to show more LOH than DGCA [12]. Accordingly, we found significantly more $\mathrm{LOH}$ at the marker loci and a higher prevalence of LOH-H in IGCA than in DGCA.

In the present study, MSI-L was found in $40 \%$ of the non-MSI-H GCAs and was associated more often with IGCA than with DGCA. As reported recently by Halford et al. [18], MSI-L is present in about $30 \%$ of colorectal, endometrial, and ovarian cancers, in contrast to $3 \%$ in breast cancer. Those authors concluded, based on its frequent presence, that MSI-L occurred as a real phenomenon in cancers that were associated with the HNPCC syndrome. However, GCA, which has also been linked to the HNPCC syndrome, was not analyzed in the study [18].

In total, $43 \%$ of the GCAs studied here were found to be genetically stable (LOH-N/MSS), with a significant association with DGCA. Previous studies have found the LOH-N type to be more prevalent $(51 \%-60 \%)$ in DGCA than in IGCA $(13 \%-50 \%)[12,26]$. However, comparison of the results is not straightforward, because the LOH-N tumors in the aforementioned studies $[12,26]$ were not stratified according to their MSI-L or MSS status. Recently, a microsatellite and chromosomally stable subgroup similar to LOH-N/MSS has been described in $17 \%-38 \%$ of colorectal cancers [29,30]. Accordingly, our data imply, as a novel finding for GCA, that the LOH-N/MSS phenotype represents a distinct subgroup which is more prevalent in DGCA than in IGCA. The carcinogenic mechanism behind this stable GCA phenotype is not understood at present, but it may involve epigenetic alterations of multiple genes, e.g., by hypermethylation of their promoter regions ([39], reviewed in [6]).

In the present study, the MSI-L phenotype was found to be significantly linked to $\mathrm{LOH}-\mathrm{H}$ cancers (Table 4). In support, Goel et al. [30] found 69.7\% (30/43) of MSIL colorectal cancers to have at least one LOH event in the seven markers analyzed. Tang et al. [29] found chromosomal instability in $91.7 \%$ (11/12) of MSI-L colorectal cancers, as assessed either by flow cytometry or by LOH analysis. Accordingly, in our study on GCA, $54.5 \%(6 / 11)$ of the MSI-L tumors showed at least one LOH. Tang et al. [29] and Goel et al. [30] suggest that, in colorectal cancers, a subgroup exists where MSI and LOH pathways overlap. Taking our findings together with these previous findings $[29,30]$, it is conceivable that, also in GCA, MSI-L represents an independent phenomenon which may be associated with the $\mathrm{LOH}$ pathway.

Variations in genetic stability may associate differently with clinicopathological parameters and survival. MSI-H has been associated with expanding growth, a high number of tumor-infiltrating lymphocytes, poor differentiation, lower clinical stage, intestinal type, lower likelihood of distant metastases, older age at detection, and better prognosis [9,11,40-43]. LOH has been shown to relate to cancer progression, where a transition from LOH-L to LOH-H is thought to reflect an increase in chromosomal instability during tumor advancement $[7,11,12]$. A poor outcome for GCA with LOH-H and LOH-N phenotypes has been reported [12]. In the present study, most likely due to the limited number of samples, the only clinicopathological differences were the younger age of DGCA patients and the higher age at the time of detection of MSI-H cancers. Also, MSI-H tumors tended to represent a lower clinical stage than LOH-N/LOH tumors. These results are in agreement with earlier observations [9,11,39-43].

In conclusion, the overall frequencies of MSI and $\mathrm{LOH}$ determined by the tetranucleotide markers were in line with previous results for GCA. Our data corroborate previous reports showing that, of the two major types of gastric cancer, IGCA comprises significantly more genomic instability, whereas in DGCA, a stable phenotype is predominant. Contrary to previous views that MSI-L would represent merely an inherent genomic instability of cancer, our data suggest that MSI-L is a true phenomenon, especially in the intestinal type of gastric cancer, and that MSI-L may be associated with the $\mathrm{LOH}$ pathway by a mechanism that is unknown at present.

Acknowledgments We thank Sari Karesvuori for management of clinical records, and Sue Hyypijev, Soili Kaliste, Eve Karvinen, Kirsti Höök, and Teija Vanhala for excellent technical assistance.

\section{References}

1. Laurén P. The two histologic main types of gastric carcinoma: diffuse and the so-called intestinal type carcinoma. An attempt at a histoclinical classification. Acta Pathol Microbiol Scand 1965;64: 31-49.

2. Watanabe H, Jass JR, Sobin LH. Histological typing of esophageal and gastric tumors. In: World Health Organization International histological classification of the tumors. 2nd ed. Berlin: Springer-Verlag; 1989. p. 20-6.

3. Ming SC. Cellular and molecular pathology of gastric carcinoma and precursor lesions: a critical review. Gastric Cancer 1998;1:3150 .

4. Fuchs CS, Mayer RJ. Gastric carcinoma. New Engl J Med 1995; 333:32-41.

5. Sipponen P, Marshall BJ. Gastritis and gastric cancer in Western countries. Gastroenterol Clin North Am 2000;29:579-92.

6. Tahara E. Genetic pathways of two types of gastric cancer. IARC Scientific Publications 2004;157:327-49.

7. Kim KM, Kwon MS, Hong SJ, Min KO, Seo EJ, Lee KY, et al. Genetic classification of intestinal-type and diffuse-type gastric cancers based on chromosomal loss and microsatellite instability, Virchows Arch 2003;443:491-500.

8. Ogata SY, Tamura G, Endoh Y, Sakata K, Ohmura K, Motoyama T. Microsatellite alterations and target gene mutations in the 
early stages of multiple gastric cancer. J Pathol 2001;194:33440.

9. Halling KC, Harper J, Moskaluk CA, Thibodeau SN, Petroni GR, Yustein AS, et al. Origin of microsatellite instability in gastric cancer. Am J Pathol 1999;155:205-11.

10. Rhyu MG, Park WS, Meltzer SJ. Microsatellite instability occurs frequently in human gastric carcinoma. Oncogene 1994;9:29-32.

11. Nishizuka S, Tamura G, Terashima M, Satodate R. Loss of heterozygosity during the development and progression of differentiated adenocarcinoma of the stomach. J Pathol 1998;185:3843.

12. Choi SW, Choi JR, Chung YJ, Kim KM, Rhyu MG. Prognostic implications of microsatellite genotypes in gastric carcinoma, Int J Cancer 2000;89:378-83.

13. Sakakura C, Mori T, Sakabe T, Ariyama Y, Shinomiya T, Date K, et al. Gains, losses and amplifications of genomic materials in primary gastric cancers analysed by comparative genomic hybridization. Genes Chromosom Cancer 1999;24:299-305.

14. Varis A, Wolf M, Monni O, Vakkari ML, Kokkola A, Moskaluk $\mathrm{C}$, et al. Targets of gene amplification and overexpression at $17 \mathrm{q}$ in gastric cancer. Cancer Res 2002;62:2625-9.

15. Boland CR, Thibodeau SN, Hamilton SR, Sidransky D, Eshleman JR, Burt RW, et al. A National Cancer Institute workshop on microsatellite instability for cancer detection and familial predisposition: development of international criteria for the determination of microsatellite instability in colorectal cancer. Cancer Res 1998;58:5248-57.

16. Laiho P, Launonen V, Lahermo P, Esteller M, Guo M, Herman $\mathrm{JG}$, et al. Low-level microsatellite instability in most colorectal carcinomas. Cancer Res 2002;62:1166-70.

17. Halford S, Sasieni P, Rowan A, Wasan H, Bodmer W, Talbot I, et al. Low-level microsatellite instability occurs in most colorectal cancers and is a nonrandomly distributed quantitative trait. Cancer Res 2002;62:53-7.

18 Halford SER, Sawyer EJ, Lambros MB, Gorman P, Macdonald ND, Talbot IC, et al. MSI-low, a real phenomenon which varies in frequency among cancer types. J Pathol 2003;201:389-94.

19. Sieben NLG, ter Haar NT, Cornelisse CJ, Fleuren GJ, CletonJansen AM. PCR artefacts in LOH and MSI analysis of microdissected tumor cells. Hum Pathol 2000:31:1414-9.

20. Thiagalingam S, Foy RL, Cheng KH, Lee HJ, Thiagalingam A, Ponte JF. Loss of heterozygosity as a predictor to map tumor suppressor genes in cancer: molecular basis of its occurrence. Curr Opin Oncol 2002;14:65-72.

21. Fleischer AS, Esteller M, Wang S, Tamura G, Suzuki H, Ying J, et al. Hypermethylation of the hMLH1 gene promoter in human gastric cancers with microsatellite instability. Cancer Res 1999;59: 1090-5.

22. Leung SY, Yuen ST, Chung LP, Chu KM, Chan ASY, Ho JCI. hMLH1 promoter methylation and lack of hMLH1 expression in sporadic gastric carcinomas with high-frequency microsatellite instability. Cancer Res 1999;59:159-64.

23. Duval A, Reperant M, Compoint A, Seruca R, Ranzani GN, Iacopetta B, et al. Target gene mutation profile differs between gastrointestinal and endometrial tumors with mismatch repair deficiency. Cancer Res 2002;62:1609-12.

24. Thiagalingam S, Laken S, Willson JKV, Markowitz SD, Kinzler $\mathrm{KW}$, Vogelstein B, et al. Mechanisms underlying losses of heterozygosity in human colorectal cancers. Proc Natl Acad Sci USA 2001;98:2698-702.

25. Lengauer C, Kinzler KW, Vogelstein B. Genetic instabilities in human cancers. Nature 1998;396:643-9.

26. Tamura G, Sakata K, Nishizuka S, Maesawa C, Suzuki Y, Terashima $\mathrm{M}$, et al. Allelotype of adenoma and differentiated adenocarcinoma of the stomach. J Pathol 1996;180:371-7.
27. Choi SW, Park SW, Lee KY, Kim KM, Chung YJ, Rhyu MG. Fractional allelic loss in gastric carcinoma correlates with growth patterns. Oncogene 1998;17:2655-9.

28. Hiyama T, Tanaka S, Yoshihara M, Sasao S, Kose K, Shima H, et al. Chromosomal and microsatellite instability in sporadic gastric cancer. J Gastroenterol Hepatol 2004;19:756-60.

29. Tang R, Changchien CR, Wu MC, Fan CW, Liu KW, Chen JS, et al. Colorectal cancer without high microsatellite instability and chromosomal instability - an alternative genetic pathway to human colorectal cancer. Carcinogenesis 2004;25:841-6.

30. Goel A, Arnold CN, Niedzwiecki D, Chang DK, Ricciardello L, Carethers JM, et al. Characterisation of sporadic colon cancer by patterns of genomic instability. Cancer Res 2003;63:160814.

31. Vauhkonen H, Hedman M, Vauhkonen M, Kataja M, Sipponen $\mathrm{P}$, Sajantila A. Evaluation of gastrointestinal cancer tissues as a source of genetic information for forensic investigations by using STRs. Forensic Sci Int 2004;139:159-67.

32. Hoang JM, Cottu PH, Thuille B, Salmon RJ, Thomas G, Hamelin R. BAT-26, an indicator of the replication error phenotype in colorectal cancers and cell lines, Cancer Res 1997;57:3003.

33. McKie AB, Filipe MI, Lemoine NR. Abnormalities affecting the APC and MCC tumor suppressor gene loci on chromosome $5 \mathrm{q}$ occur frequently in gastric cancer but not in pancreatic cancer. Int J Cancer 1993;55:598-603.

34. Fang DC, Jass JR, Wang DX. Loss of heterozygosity and loss of expression of the DCC gene in gastric cancer. J Clin Pathol 1998; 51:593-6.

35. Carvalho R, Kayademir T, Soares P, Canedo P, Sousa S, Oliveira $\mathrm{C}$, et al. Loss of heterozygosity and promoter methylation, but not mutation, may underlie loss of TFF1 in gastric carcinoma. Lab Invest 2002;82:1319-26.

36. Habano W, Sugai T, Nakamura SI, Uesugi N, Yoshida T, Sasou S. Microsatellite instability and mutation of mitochondrial and nuclear DNA in gastric carcinoma. Gastroenterology 2000;118: 835-41.

37. Buonsanti G, Calistri D, Padovan L, Luinetti O, Fiocca R, Solcia E, et al. Microsatellite instability in intestinal- and diffuse-type gastric carcinoma. J Pathol 1997;182:167-73.

38. Hayden JD, Cawkwell L, Dixon MF, Pardal F, Murgatroyd H, Gray S, et al. A comparison of microsatellite instability in early onset gastric carcinomas from relatively low and high incidence European populations. Int J Cancer 2000;85:189-91.

39. Toyota M, Ahuja N, Suzuki H, Itoh F, Ohe-Toyota M, Imai K, et al. Aberrant methylation in gastric cancer associated with the CpG island methylator phenotype. Cancer Res 1999;59:543842.

40. Ottini L, Palli D, Falchetti M, D'Amico C, Amorosi A, Saieva C, et al. Microsatellite instability in gastric cancer is associated with tumor location and family history in high-risk population from Tuscany. Cancer Res 1997;57:4523-9.

41. Grogg KL, Lohse CM, Pankratz VS, Halling KC, Smyrk TC. Lymphocyte-rich gastric cancer: associations with Epstein-Barr virus, microsatellite instability, histology, and survival. Mod Pathol 2003;16:641-51.

42. Yamamoto H, Perez-Piteira J, Yoshida T, Terada M, Itoh F, Imai $\mathrm{K}$, et al. Gastric cancers of the microsatellite mutator phenotype display characteristic genetic and clinical features. Gastroenterology 1999;116:1348-57.

43. Oliveira C, Seruca R, Seixas M, Sobrinho-Simões M. The clinocopathological features of gastric carcinomas with microsatellite instability may be mediated by mutations of different target genes. A study of the TGFBRII, IGFII, and $B A X$ genes. Am J Pathol 1998;153:1211-9. 